NASA-TM-112159

\title{
Simultaneous Luminescence Pressure and Temperature Measurement System for Hypersonic Wind Tunnels Gregory M. Buck
}

Reprinted from

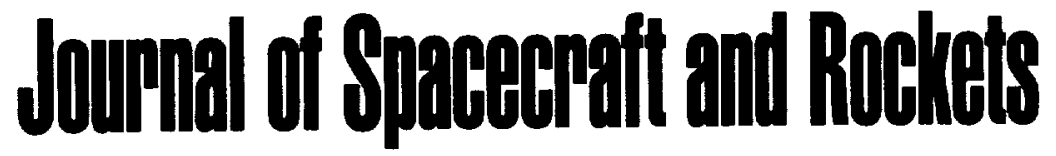

Volume 32, Number 5, Pages 791-794

\section{OAIAA:}

A publication of the

American Institute of Aeronautics and Astronautics, Inc.

370 L'Enfant Promenade, SW

Washington, DC 20024-2518 



\title{
Simultaneous Luminescence Pressure and Temperature Measurement System for Hypersonic Wind Tunnels
}

\author{
Gregory M. Buck* \\ NASA Langley Research Center, Hampton, Virginia 23681-000I
}

\begin{abstract}
Surface pressures and temperatures are determined from visible emission brightness and green-to-red color ratioing of induced luminescence from a ceramic surface with an organic dye coating. A ceramic-dye matrix of porous silica ceramic with an adsorbed dye is developed for high-temperature pressure sensitivity and stability (up to $150^{\circ} \mathrm{C}$ ). Induced luminescence may be excited using a broad range of incident radiation from visible blue light $(488-\mathrm{nm}$ wavelength) to the near ultraviolet $(365 \mathrm{~nm})$. Ceramic research models and test samples are fabricated using net-form slip-casting and sintering techniques. Methods of preparation and effects of adsorption film thickness on measurement sensitivity are discussed. With the present 8-bit imaging system a $10 \%$ pressure measurement uncertainty from 50 to 760 torr is estimated, with an improvement to $5 \%$ from 3 to 1500 torr with a 12-bit imaging system.
\end{abstract}

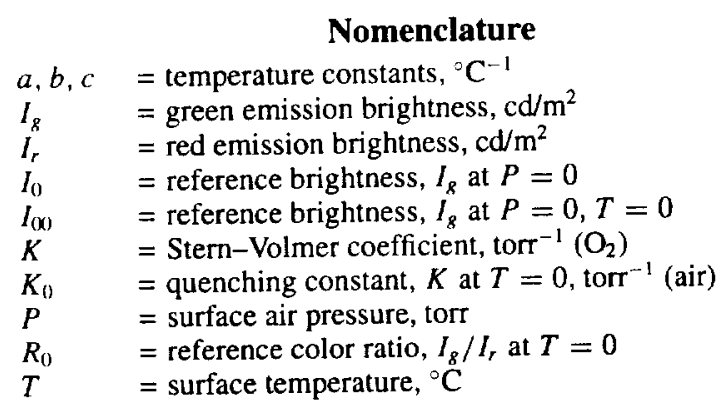

\section{Introduction}

DVANCED diagnostic techniques capable of nonintrusive global measurement of aerodynamic pressure and heating distributions on models tested in hypersonic wind tunnels will significantly enhance the design and assessment of future aerospace vehicles. Considerable progress has been made in measuring global temperature distributions with time (hence global heating distributions via relative-intensity thermographic phosphor and infrared emission techniques), but a quantitative technique for global pressure measurements at hypersonic conditions has yet to be developed. Pressure mapping techniques using photoluminescence offer potential savings in time and expense for wind-tunnel testing over conventional pressure instrumentation (i.e., discrete measurements via transducers) and are sought for hypersonic wind-tunnel applications.

Luminescence pressure mapping techniques have been developed and tested broadly by NASA centers, industries, and universities for lower-speed applications. ${ }^{1,2}$ Current techniques use oxygensensitive luminophores in polymer binders for pressure sensitive paints which can be applied to a variety of surfaces. In high-speed applications with aerodynamic heating, however, temperature effects on induced luminescence complicate pressure measurements and should be given the uppermost attention in the case of hypersonic flows.

Recent work ${ }^{3}$ was done to calibrate temperature effects on the luminescence of a paint for high-speed applications, but it was later

Presented as Paper 94-2482 at the AIAA 18th Aerospace Ground Testing Conference, Colorado Springs, CO, June 20-23, 1994; received July 13, 1994; revision received June 27, 1995; accepted for publication July 3, 1995. Copyright (C) 1995 by the American Institute of Aeronautics and Astronautics, Inc. No copyright is asserted in the United States under Title 17, U.S. Code. The U.S. Government has a royalty-free license to exercise all rights under the copyright claimed herein for Governmental purposes. All other rights are reserved by the copyright owner.

*Aerospace Engineer, Aerothermodynamics Branch. Member AIAA. demonstrated $^{4}$ that temperature significantly affects the response of this paint and that past a certain temperature threshold $\left(40-60^{\circ} \mathrm{C}\right)$ the luminescence degradation becomes irreversible.

Improved techniques and materials for hypersonic testing would include an internal method for thermal calibration and highertemperature stability.

\section{Approach}

The approach taken in this work was to adapt or develop a technique for simultaneous luminescence pressure and temperature measurement with materials having higher temperature sensitivity and stability than current paint applications. There are many different combinations of oxygen-sensitive luminophores, binding matrices, and substrates that may be adapted. ${ }^{5}$

Early applications for flow visualization used a pressure-sensitive coating with an adsorbed dye on silica gel powder mixed with a polymer binder. ${ }^{6}$ A more recent application of an adsorbed dye demonstrated microsecond time response on a ceramic surface. ${ }^{7}$ In typical paint applications, oxygen diffusion rates and solubility in polymers lead to response times from several milliseconds to as long as seconds. In Ref. 7, an adsorbed porphyrin dye on a silica matrix yielded response times measuring less than $50 \mu$ s. Other applications without polymer binders, such as a porphyrin dye adsorbed directly on a painted surface, have displayed nearly instantaneous pressure response in wind-tunnel testing. ${ }^{8} \mathrm{~A}$ dye adsorption method may have other advantages, such as higher temperature stability, since thermal degradation is also frequently attributed to breaking down of polymer binders.

At NASA Langley Research Center, integrated research models are routinely cast from ceramics and tested using luminescence diagnostics. Insulated test models of silica ceramic are net-cast and sintered using patented procedures. A two-color luminescence thermography technique using ceramic phosphor coatings and digital color video equipment is used for quantitative temperature mapping and heat transfer analysis. ${ }^{9}$ Color ratioing techniques have also been used for temperature mapping with phase-change paints and liquid crystals. ${ }^{10}$

In detail, the approach taken was to test various dye adsorptions on net-cast ceramics for stability, pressure response, and color change with temperature. A two-color digital video analysis system was used to acquire and analyze data.

\section{Experiments and Results}

\section{Materials and Diagnostics}

The effects of oxygen interaction on luminescence yields and lifetimes are well documented for many substances, since oxygen is an active quencher of fluorescence and phosphorescence. For some materials, quenching rates and efficiencies are large enough to make 
them useful as oxygen indicators. Theory predicts the quenching process to obey the Stern-Volmer equation

$$
\frac{I}{I_{0}}=\frac{1}{1+K\left[\mathrm{O}_{2}\right]}
$$

In a mixed gas such as air, the oxygen concentration is simply replaced by the partial gas pressure. The quenching coefficient $K$ can be calibrated for many different luminophores.

Few guidelines exist for the temperature dependence of luminescence in oxygen sensors. Temperature is known, however, to affect quantum yield, quenching (Stern-Volmer) coefficient, and solubility and diffusion rates in binders.

Various dye applications were first applied to cast silica ceramic samples. Metered concentrations and amounts were droppered on the surface and air-dried.

Luminescence brightness and color were measured in an insulated vacuum oven through a quartz glass window using simultaneous green- and red-filtered digitized camera images:

$$
\begin{aligned}
& I_{g}=\int s_{g}(\lambda) I(\lambda) \mathrm{d} \lambda \\
& I_{r}=\int s_{r}(\lambda) I(\lambda) \mathrm{d} \lambda
\end{aligned}
$$

where $I(\lambda)$ is the surface emission intensity as a function of wavelength, and $s_{g}(\lambda)$ and $s_{r}(\lambda)$ are the green and red detector sensitivities, respectively.

Samples studied included an adsorbed porphyrin dye ${ }^{1}$ and an organic perylene dye, which is a commercially manufactured product used in coloring plastics (Fluorol, Green Gold 084). In initial tests, the porphyrin dye was permanently vaporized or degraded at oven temperatures approaching $60^{\circ} \mathrm{C}$. The porphyrin emission spectrum was also monocolored, with no significant shift in color with temperature or pressure. The perylene dye had bright luminescence and pressure sensitivity up to temperatures exceeding $150^{\circ} \mathrm{C}$ It has yielded ${ }^{5}$ green emission $(520 \mathrm{~nm})$ with blue-light excitation $(460 \mathrm{~nm})$, but an additional component of red emission was also found on ceramic samples. The adsorbed perylene dye also exhibited a useful color shift with temperature

Effects on luminescence brightness for the adsorbed perylene dye could be approximated to first order by a linear shift in quantum efficiency and quenching coefficient with constants $a$ and $b$ :

$$
\frac{I_{R}}{I_{(N)}}=\frac{1+a T}{1+K_{0}(1+b T) P}
$$

The effect on the green-to-red color ratio could also be approximated linearly:

$$
I_{g} / I_{r}-R_{0}=c T
$$

The temperature coefficient $c$ was found to be constant over a broad range of applications, but other characteristics seemed highly dependent on surface preparation. $R_{0}$ was found to drift substantially, but stabilized after an initial baking at maximum temperature. Sample-to-sample and surface variations in $R_{0}$ are thought to be associated with adsorbed film thickness.

The same effects on brightness and color ratio were shown with blue-light ( $488 \mathrm{~nm}$, argon laser) and ultraviolet $(365 \mathrm{~nm}$, mercury lamp) excitation for temperatures up to $150^{\circ} \mathrm{C}$. Plots of Eqs. (4) and (5) are shown in Figs. 1 and 2 with observed coefficient values for $K_{i}, a, b$, and $c$.

\section{Data Acquisition and Processing}

In making measurements with this type of system, the variables $K_{0}, a, b$, and $c$ are approximated as constants at all points on a sample or model surface, and $I_{(0)}$ and $R_{0}$ are calculated at each point using wind-off measurements of color brightness at static pressure and temperature with Eqs. (4) and (5):

$$
I_{g 1}(x, y), I_{r 1}(x, y), P_{1}, T_{1} \rightarrow I_{00}(x, y), R_{0}(x, y)
$$

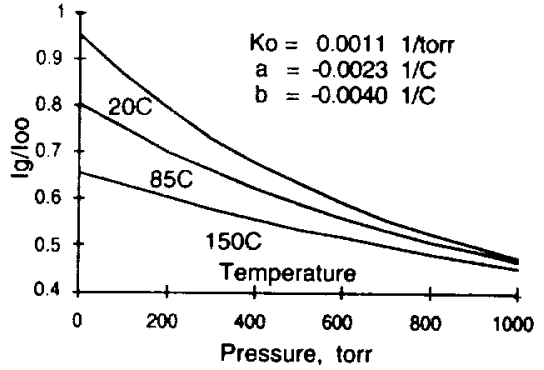

Fig. 1 Emission brightness vs pressure model at constant temperatures.

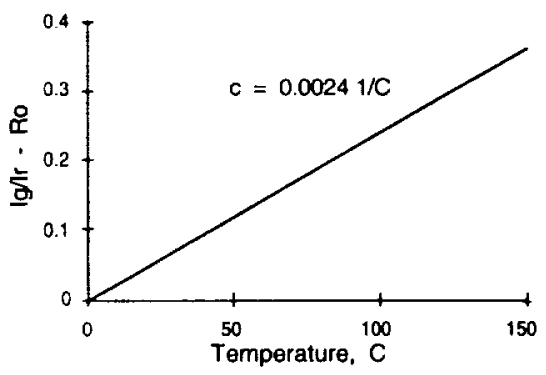

Fig. 2 Ratio difference vs temperature.

During subsequent wind-on experiments, Eqs. (4) and (5) are again used to calculate pressure and temperature distributions with color brightness images and previously calculated values of $I_{00}$ and $R_{0}$ at each point:

$$
I_{g 2}(x, y), I_{r 2}(x, y),\left[I_{(x)}(x, y), R_{0}(x, y)\right] \rightarrow P_{2}(x, y), T_{2}(x, y)
$$

\section{Preliminary Wind-Tunnel Testing}

Following initial investigations on test samples, research models were prepared and tested in the 31 -in. Mach 10 tunnel at NASA Langley, providing mixed results. Applications primarily demonstrated a need for improving model preparation and dye application techniques. Perylene dye was applied to research test models in solution with toluene by dipping, spraying, and brushing. In each case, however, the sensitivity and brightness were much lower than with previous test samples. The poor performance was connected with surface preparation and dye application methods, which varied significantly.

Ceramic research models that had been tested with luminescence and infrared thermography techniques, included an 0.02 scale model of a proposed personnel launch vehicle (HL-20) and an 0.0075 -scale Shuttle Orbiter model.

Although quenching coefficients were substantially lower in model preparations, and difficult to measure with the current 8-bit imaging system, the luminescence brightness was shown to be stable before and after runs except in stagnation regions that exceeded $200^{\circ} \mathrm{C}$. Ultraviolet excitation $(365 \mathrm{~nm})$ was used in wind-tunnel setups. Advantages found in using ultraviolet lamps over other sources were readily accessible lamp supplies (mercury-arc lamps), which are currently used for luminescence thermography, lower cost than with blue-light lasers and xenon lamps, and simpler and more efficient image filtering with better excitation and visible-emission wavelength separation. A possible disadvantage with ultraviolet excitation is photodegradation of the dye, although none was observed during these and later tests.

\section{Development and Testing of Application Methods}

Further testing was performed in a vacuum oven chamber for development of dye application methods. A subsequent method has been developed for consistent sample and model application. Effects of film thickness are also analyzed for development of optimum dye concentrations and application techniques.

The original test samples were ceramic disks on which a carefully controlled concentration and amount of dye was droppered on the 
surface. On subsequent research models it was found that the tendency was to over-coat the surface, which was shown to significantly decrease quenching coefficients from the original test samples. The next set of samples were then prepared as a model surface might be, with a saturating brush or dipping application for uniformity.

In the subsequent method, a sample or model surface is first polished with successively finer grits of silicon carbide paper to a highly smooth finish ( 600 grit or finer). The polishing residue is removed with solvent. The surface is then saturated by brush or dipped in a specific dye concentration with toluene. It is then allowed to dry and baked in a clean convection oven for $30 \mathrm{~min}$ at $150^{\circ} \mathrm{C}$. Finally, the surface is repolished lightly with 600-grit or finer silicon carbide paper, thus removing exposed dye layers and isolating dye adsorption to ceramic pores, which can be regulated by controlling the dye concentration. Repeatability of pore size and distribution in the ceramic casting and sintering process is then also important in regulating dye adsorption and film thickness.

For these tests, ceramic disk samples were machined from slipcast silica rods $(1 \times 12.7 \mathrm{~mm}$ diam $)$. Samples were drilled and mounted to electrical connectors on an alumina ceramic backing with fine thermocouple wire (0.076-mm diam, type $\mathrm{K})$ butt-welded at the center and secured with $0.51-\mathrm{mm}$-diam leads at the connectors. As many as five test samples were mounted as shown in Fig. 3.

Different regions on the test samples were analyzed as indicated in Fig. 3 with numbers 1 through 4 , as viewed by the camera through the test-chamber window. The sample from which region 1 was taken was prepared with low dye concentration. Regions 2 and 3 are from a test sample with optimum dye concentration, and region 4 from one with high dye concentration.

The chamber pressure was controlled via a vacuum pump and venting to atmosphere and was measured with a 1000 -torr variablecapacitance pressure transducer and Hastings vacuum gauge down to 0.1 torr. Chamber insulation was effective in providing stable temperatures up to $150^{\circ} \mathrm{C}$, and it took approximately 4 to $6 \mathrm{~h}$ for the chamber to cool from $150^{\circ} \mathrm{C}$ to room temperature at 0.5 torr.

Data for image sampling regions were averaged from $10 \times 10$ element pixel arrays. Brightness was calibrated at each sample region using a calibrated uniform-intensity light source, or integrating sphere, with micrometer-controlled aperture brightness and 2855-K color temperature (photometric units of $\mathrm{cd} / \mathrm{m}^{2}$ ). The results are shown in Fig. 4.

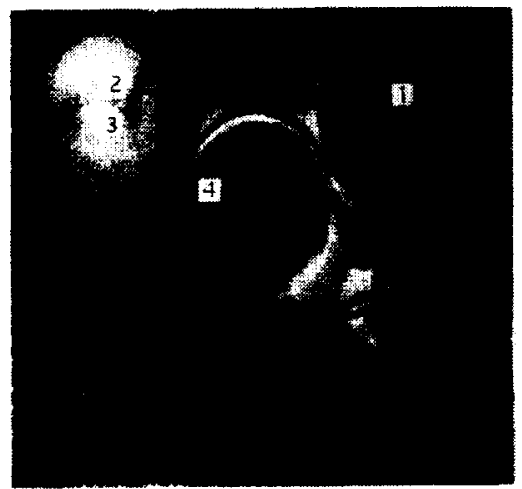

Fig. 3 Test samples with image sampling regions in vacuum oven experiment.

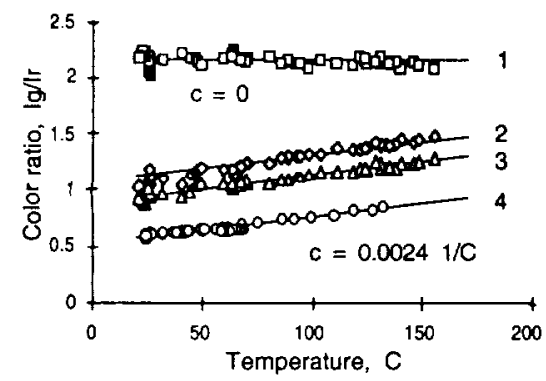

Fig. 4 Color-ratio data vs temperature for sampling regions 1 through 4.

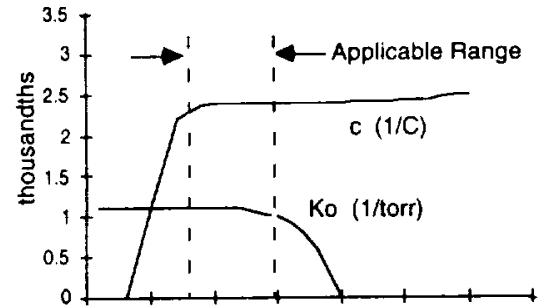

a) Temperature and quenching constants

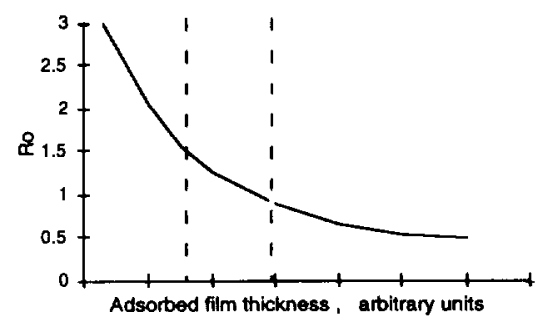

b) Reference color ratio

Fig. 5 Observed effects of adsorbed film thickness.

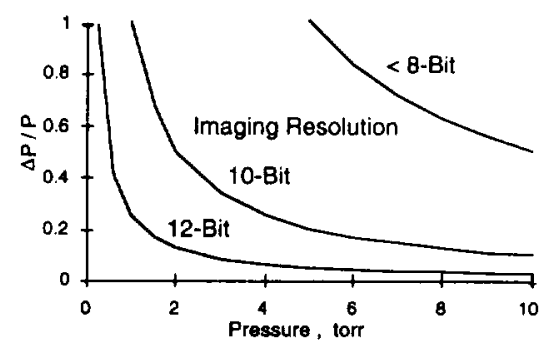

a) Relative

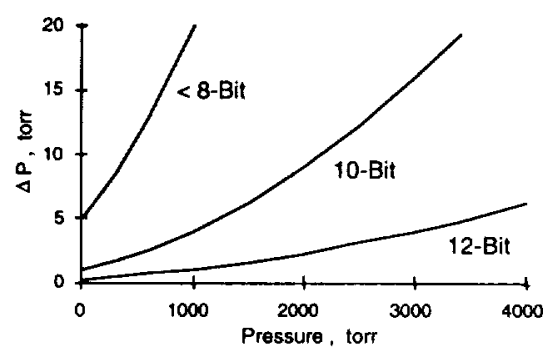

b) Absolute

Fig. 6 Pressure measurement uncertainty with imaging resolution.

$R_{0}$ is shown to vary from regions 2 to 3 on the same sample disk. The temperature coefficient $c$ is shown, however, to be constant for regions 2 through 4 , approaching zero in region 1 for a thinner adsorption layer. The quenching constants for regions 1 through 3 are approximately equal $\left(K_{0}=0.0011\right.$ torr $\left.^{-1}\right)$, with a much lower value for region $4\left(K_{0}=0.0005\right.$ torr $\left.^{-1}\right)$.

From these data and similar observations, Figs. 5a and $5 \mathrm{~b}$ were constructed as a guide for future dye applications. Stable values of the temperature sensitivity and quenching constants $\left(c\right.$ and $K_{0}$ ) are shown to exist over a range of film thicknesses corresponding to a range of calibration coefficient $R_{0}$ roughly from 0.9 to 1.4

Other effects on the quenching coefficient may include ceramic contaminants, interference from humidity and other gases, and later surface contamination from handling and tunnel environments. Possible humidity effects, as noted in some of the vacuum-oven experiments, are expected to be less of a concern in the drier air supplies for wind-tunnel diagnostics. Control of other contaminants must be incorporated in model preparation and handling procedures.

\section{Accuracy of Measurements}

In vacuum-oven experiments as well as in later tunnel applications, both sensible-pressure range and resolution are limited by 
the dynamic resolution of the imaging system and the quenching coefficient, which also varies with temperature.

The pressure measurement uncertainty can be derived from Eq. (1) as a quadratic function of pressure:

$$
\Delta P=\frac{\Delta I}{I_{0}} \frac{(1+K P)^{2}}{K}
$$

Values of $\Delta I / I_{0}$ used in uncertainty calculations are $200^{-1}, 1000^{-1}$, and $4000^{-1}$, representing present 8-bit imaging capability and estimated performance for 10-bit and 12-bit systems. Figures $6 a$ and $6 b$ show calculations with $K=0.001$ tor $^{-1}$ (nominal sensitivity at $25^{\circ} \mathrm{C}$ ) plotted as relative pressure uncertainty in vacuum and absolute uncertainty over the entire pressure range. With the present system a $10 \%$ pressure measurement uncertainty from 50 to 760 torr is estimated, improving to 5\% from 3 to 1500 torr with a 12-bit imaging system.

\section{Summary}

Development of a ceramic-dye matrix and a digital color imaging system has great potential for simultaneous global pressure and temperature mapping. It was found that an adsorbed perylene dye on slip-cast silica is pressure (oxygen) sensitive and reusable to fairly high temperatures $\left(\approx 150^{\circ} \mathrm{C}\right)$. It was also found that adsorbed luminescence has an approximately linear color shift with temperature, which can be used with a two-color imaging system for simultaneous pressure and temperature measurement in hypersonic wind tunnels. With the present 8-bit imaging system a $10 \%$ pressure measurement uncertainty from 50 to 760 torr is estimated, improving to $5 \%$ from 3 to 1500 torr with a 12-bit imaging system.

\section{Acknowledgments}

The author is grateful to several individuals and groups at NASA Langley-in particular, Don Oglesby for providing initial dye sam- ples, Bill Hood for creation of test apparatus, and Mike Powers, Mark Griffith, and Harry Walthall for ceramic fabrication.

\section{References}

'Kavandi, J., Callis, J., Gouterman, M., Khalil, G., Wright, D., Green, E., Burns, D., and McLachlan, B., "Luminescent Barometry in Wind Tunnels," Review of Scientific Instruments, Vol. 61, No. 11, 1990, pp. 3340-3347.

${ }^{2}$ Morris, M. J., Donovan, J. F., Kegelman, J. T., Schwab, S. D., Levy, R. L., and Crites, R. C., "Aerodynamic Applications of Pressure-Sensitive Paint," AIAA Paper 92-0264, Jan. 1992.

${ }^{3}$ Morris, M. J., and Donovan, J. F., "Application of Pressure- and Temperature-Sensitive Paints to High-Speed Flows," AIAA Paper 94-2231, June 1994.

${ }^{4}$ Jules, K., Carbonaro, M., and Zemsch, S., "Application of Pressure Sensitive Paint in Hypersonic Flows," NASA TM-106824, Feb. 1995.

${ }^{5}$ Wolfbeis, O. S.. "Oxygen Sensors," Fiber Optic Chemical Sensors and Biosensors, 1st ed., CRC Press, Boca Raton, FL, 1991, Vol. 2, pp. 19-53.

${ }^{6}$ Peterson, J. I., and Fitzgerald, R. V., "New Technique of Surface Flow Visualization Based on Oxygen Quenching of Fluorescence," Review of Scientific Instruments, Vol. 51, No. 5, 1980, pp. 670,671.

'Baron, A. E., Danielson, J. D. S., Gouterman, M., Wan, J. R., Callis, J. B., and McLachlan, B., "Sub-Millisecond Response Times of Oxygen Quenched Luminescent Coatings," Review of Scientific Instruments, Vol. 64, No. 12, 1993, pp. 3394-3402.

${ }^{8}$ Sellers, M. E., and Brill, J. A., "Demonstration Test of Pressure Sensitive Paint in the AEDC 16-ft Transonic Wind Tunnel Using the TST Model," AIAA Paper 94-2481, June 1994.

${ }^{9}$ Buck, G. M., "Surface Temperature/Heat-Transfer Measurement Using a Quantitative Phosphor Thermography System," AIAA Paper 91-0064, Jan. 1991 .

${ }^{10}$ Buck, G. M., "Automated Thermal Mapping Techniques Using Chromatic Image Analysis," NASA TM-101554, April 1989.

J. C. Adams Associate Editor 